\title{
"Mas seja tudo pelo bem da física": aspectos da trajetória científica de Francisco Xavier Roser, SJ (1904-1967)
}

\author{
"May all be for the sake of physics": notes on the scientific trajectory of Francisco Xavier Roser, SJ
} (1904-1967)

\author{
Bruno Nobre ${ }^{1}$, Antonio Augusto Passos Videira*1 \\ ${ }^{1}$ Universidade do Estado do Rio de Janeiro, Rio de Janeiro, RJ, Brasil.
}

Recebido em 23 de Junho, 2017. Revisado em 08 de Agosto, 2017. Aceito em 17 de Agosto, 2017.

\begin{abstract}
O artigo descreve a trajetória científica do físico e padre jesuíta Francisco Xavier Roser, fundador do Departamento de Física da Pontifícia Universidade Católica do Rio de Janeiro, e um dos pioneiros do estudo da radioatividade natural no Brasil. Além de uma nota biográfica, o artigo apresenta e discute os principais aspetos e relevância da atividade científica do Pe. Roser.

Palavras-chave: Física Experimental, Raios Cósmicos, Radioatividade Natural, Companhia de Jesus, Pontifícia Universidade Católica.
\end{abstract}

\begin{abstract}
The article describes the scientific trajectory of the physicist and Jesuit priest Francisco Xavier Roser, who is the founder of the Physics Department of the Pontifical Catholic University of Rio de Janeiro, and one of the pioneers of the study of natural radioactivity in Brazil. The article includes a biography and a discussion on the most relevant aspects of Fr. Roser's scientific career.

Keywords: Experimental Physics, Cosmic Rays, Natural Radioactivity, Society of Jesus, Pontifical Catholic University
\end{abstract}

\section{Introdução}

No presente artigo, descrevemos os aspectos mais significativos da trajetória científica do físico e padre jesuíta Francisco Xavier Roser (1904-1967), professor e fundador, em 1957, do então Instituto (hoje Departamento) de Física da Pontifícia Universidade Católica do Rio de Janeiro (PUC-Rio) (Fig. 1). Roser pode ser considerado como um dos pioneiros do estudo da radioatividade natural no Brasil, o que levou o governo brasileiro a convidá-lo para integrar comitivas oficiais que representaram o Brasil em reuniões da Organização das Nações Unidas (ONU) sobre os efeitos da radioatividade nos seres vivos. Outro aspecto interessante da sua trajetória profissional foi a sua atuação como docente em instituições de ensino ligadas à Companhia de Jesus. Neste artigo, daremos especial atenção às atividades que realizou a partir do início da década de 1950, época em que a sua carreira científica se consolida. De fato, foi a partir do ano 1948 que Roser começou a se envolver, por decisão do seu superior jesuíta, na criação de um instituto de ciências naturais na Universidade Católica do Rio de Janeiro, a atual PUC-Rio.

Não é incomum encontrar referências a Roser em artigos de história da física brasileira. No entanto, estas referências são vagas e incompletas. Os quatro artigos

*Endereço de correspondência: guto@cbpf.br

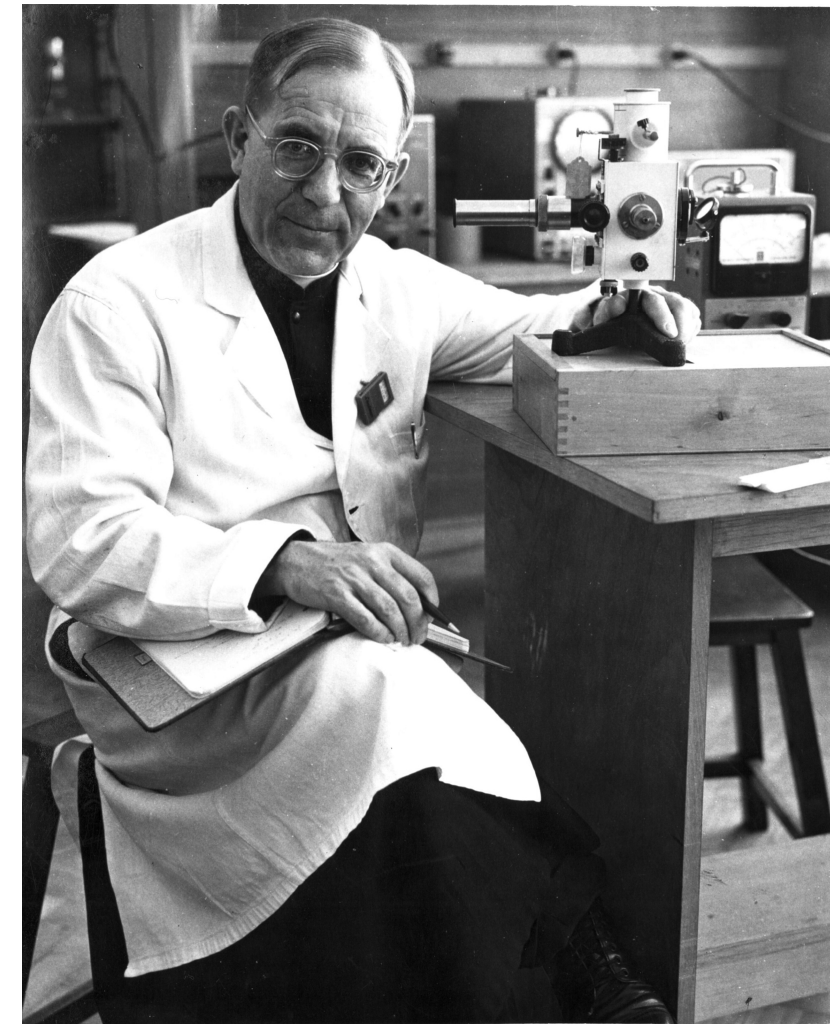

Figura 1: Pe. Roser no seu laboratório na PUC-Rio, provavelmente em meados da década de 1960. 
biográficos de que dispomos foram redigidos por pessoas que com ele conviveram, e têm, compreensivelmente, um caráter mais de memória do que de análise [1]. Embora contribua para colmatar esta lacuna, este artigo não se pretende mais do que uma primeira exposição sobre um dos primeiros físicos profissionais no Brasil, formados antes do início da Segunda Guerra Mundial.

A documentação analisada para a redação deste trabalho pode ser encontrada, sobretudo, em dois locais: a Cúria da Província Brasileira da Companhia de Jesus e o Núcleo de Memória da PUC, ambos situados na cidade do Rio de Janeiro 1

\section{Notas biográficas}

Em 1957, uma revista austríaca, dedicada às atividades profissionais e pastorais dos jesuítas daquele país, publicou uma pequena reportagem sobre um ex-compatriota seu, agora naturalizado brasileiro. Com o título "Maldição ou Benção do Átomo", o artigo de quatro páginas descrevia a atuação do físico e jesuíta Francisco Xavier Roser [2]. A julgar pelas ações e pelos ideais do Pe. Roser, tal como descritos na publicação, o átomo não seria nem uma benção, mesmo que criado por Deus, nem uma maldição, ainda que os seres humanos já tivessem empregado os conhecimentos de física atômica para fins horríveis e condenáveis.

Procurando mostrar aos seus leitores - católicos em sua maioria - a relevância da ciência no mundo contemporâneo, a revista apresentava a trajetória científica de Roser em tons simpáticos, sem esquecer alguns detalhes biográficos como, por exemplo, as razões pelas quais Roser acabou por se radicar no Brasil. Ainda que de modo discreto, a revista parecia concordar com a 'mensagem encarnada' na figura do jesuíta austríaco-brasileiro: a convicção de que o estudo e a pesquisa científica são fundamentais para o conhecimento da natureza e o lugar que o ser humano nela ocupa. A vida do Pe. Roser, principalmente nos seus últimos 27 anos, tinha sido dedicada ao estudo e à investigação em física. Em suma, o artigo procurava defender a importância de os jesuítas se dedicarem à ciência de modo profissional.

Francis Xavier Roser nasceu em St. Martin im Mühlkreis (Áustria) a 14 de novembro de 1904, ao que tudo indica no seio de uma família de proveniência rural. Iniciou seus estudos formais em 1916 na pequena cidade de Freinberg, próxima de Linz, concluindo-os oito anos depois na cidade de Kalksburg, não muito distante de Viena. Nesta última escola, fundada pelos jesuítas na

\footnotetext{
1 Ao longo do artigo, as notas bibliográficas das cartas do Pe. Roser incluirão, por esta ordem, o destinatário, o local e data de envio, e o local onde se encontram arquivadas: Arquivo da Cúria da Província Brasileira da Companhia de Jesus (ACP) ou Núcleo de Memória da PUC-Rio (NMPUC). As cartas depositadas na Cúria não estão catalogadas. Também foi consultado o Arquivo da Cúria Geral da Companhia de Jesus, em Roma. Por uma regra interna, a documentação posterior ao no de 1939 não está liberada para consulta.
}

segunda metade do século XIX, preparava-se, provavelmente, para ingressar na vida religiosa. Sabe-se que Roser alimentava o sonho de vir para o Brasil a fim de colaborar na missão de evangelização de populações indígenas da região amazônica e do Mato Grosso. De modo a realizar sua vocação, viajou para o Brasil, onde chegou a 19 de setembro de 1924, dois meses antes de completar 20 anos de idade, seguindo diretamente para o noviciado dos jesuítas na cidade de Nova Friburgo (RJ), onde passou os seis primeiros anos de formação como religioso. Segundo um relato, reproduzido em várias publicações, os seus superiores religiosos perceberam, ainda durante a sua primeira etapa de formação, o seu interesse pelas ciências naturais e, por isso, o persuadiram a especializar-se na área científica [Cf. Cullen [1], p. 122].

O esforço dos superiores religiosos de Roser no sentido de encorajar jovens jesuítas a dedicar-se ao estudo e investigação em áreas científicas deve ser entendido à luz da longa tradição de jesuítas que deram contribuições importantes em várias áreas das ciências naturais, em particular a física. Basta lembrar nomes como Cristophorus Clavius (1538-1612), matemático e um dos maiores astrónomos da época entre Copérnico e Galileu, Matteo Ricci (1552-1610), jesuíta italiano que se notabilizou pela transmissão da ciência moderna na China, ou o jesuíta Croata Roger Joseph Boscovich (1711-1787), matemático, astrónomo e físico, e um dos percursores da teoria atómica. Vale a pena lembrar, por ser mais recente e também por ter dado um contributo numa área científica mais próxima da de Roser, o jesuíta japonês Michael Yanase, que foi aluno de doutorado de Wigner [3].

Completada a formação inicial na Companhia de Jesus, Roser foi enviado para a Áustria, onde deveria estudar teologia em vista à ordenação sacerdotal e, ao mesmo tempo, estudar física. Roser chegou ao seu país natal em 1933 ou no ano seguinte (não se conhece com exatidão a data de sua chegada), e viveu durante cerca de um ano em Viena. Na capital austríaca, estudou nos institutos dos professores Egon Ritter von Schweidler (1873-1948, físico experimental) e Philipp Furtwängler (1869-1940, matemático). Não dispomos de informação relativa ao seu plano de estudos na universidade vienense. Um ano depois, transferiu-se para a Universidade de Innsbruck, onde estudou, ao mesmo tempo, física e teologia. Obteve o título de doutor em física, tendo como orientador Victor Hess, prêmio Nobel da Física em 1936, e um dos descobridores dos raios cósmicos, tema da tese de Roser. Dois anos depois, já ordenado padre, Roser defendia sua tese de doutoramento, de natureza experimental e com dados coletados no Monte Hafelekar, sede de um observatório, fundado anos antes pelo próprio Hess, para observação e estudo dos raios cósmicos. Sobre sua pesquisa no Monte Hafelekar, conhecemos o seguinte:

Todos os dias tinha que subir até ao topo de Monte Hafelekar, andando às vezes sobre caminhos onde a neve atingia alguns metros de 
espessura. Pacientemente recolhia dados sobre as variações dos raios cósmicos em relação à temperatura e à pressão barométrica, às horas do dia e às horas do ano. Finalmente, em 1938, apresentou sua Tese sobre raios cósmicos e recebeu o título de Doutor [Cullen [1], p. 122].

Fato curioso é que, aparentemente, Hess somente tomou conhecimento do resultado formal da pesquisa encetada pelo seu orientando anos depois, já nos EUA, país onde se refugiara em 1938, uma vez que sua mulher era judia. Em 1940, num artigo de revisão sobre as medidas obtidas no observatório do Monte Hafelekar, publicado na Phyical Review, Hess comenta que tinha recebido há pouco um exemplar da tese de seu ex-aluno [4].

Pouco depois de ter concluído os seus estudos, Roser regressou ao Brasil, fixando-se, mais uma vez, em Nova Friburgo, onde lhe foi confiada a missão de ensinar matemática e física ao nível secundário e superior. Antes, porém, fez a terceira provação (1939) na cidade de Pareci Novo (RS), e fez os últimos votos, sendo assim definitivamente incorporado na Companhia de Jesus ${ }^{2}$

É interessante notar que o Pe. Roser não professou o quarto voto, de obediência ao Papa em vista das missões, próprio dos membros professos da Companhia de Jesus. Tal deve-se, certamente, ao facto de ter feito simultaneamente os seus estudos de teologia e o doutorado em física, o que não lhe terá possibilitado o aprofundamento teológico necessário para ser professo de quatro votos. Esta opção significaria que Roser não poderia ocupar certos cargos de governo na Companhia de Jesus. Ao que tudo indica, Roser nunca se lamentou, pelo menos publicamente, de ter feito essa opção, o que sugere que a sua vocação científica era para ele tão importante quanto a sua vocação religiosa.

Entre 1940 e 1946, Roser exerceu várias atividades pedagógicas em Nova-Friburgo, sobressaindo a sua preocupação em fomentar entre os jovens estudantes o interesse e o gosto pelas ciências naturais. Sobre a sua influência junto dos estudantes jesuítas, é particularmente significativa a declaração do Padre Henrique Lima Vaz (1921-2002), jesuíta e um dos mais relevantes filósofos brasileiros do último quartel do século passado:

Entre os meus professores, dois, sobretudo, exerceram sobre mim uma influência decisiva: o Pe. Eduardo Magalhães Lustosa e o Pe. Francisco Xavier Roser, ambos já falecidos. (...) O Pe. Roser foi nosso professor de Matemática e Física e de uma disciplina que nos abria um horizonte novo e insuspeitado, a nós que vínhamos diretamente dos textos de Aristóteles e de Santo Tomás: "Questões científicas ligadas à Filosofia". Era toda a significação filosófica da ciência moderna que pas-

2 A terceira provação é a etapa final da formação dos jesuítas e tem, habitualmente, a duração de cerca de um ano. sava a desafiar os noviços aristotélico-tomistas que então éramos [[3], p.10] 5 .

As atividades docentes eram acompanhadas de frequentes solicitações, junto dos seus superiores, de recursos financeiros, com o objetivo de adquirir livros para a biblioteca e aparelhos para equipar os laboratórios. Sobressai, também, o seu esforço no sentido de organizar uma equipe de professores e auxiliares competentes o suficiente para ensinar conteúdos científicos atualizados. Aliás, esta é uma das características mais marcantes de Roser ao longo de toda a sua trajetória como professor e acadêmico: a preocupação constante em despertar vocações científicas, criar equipes de professores e pesquisadores, equipar laboratórios e atualizar o acervo bibliográfico das bibliotecas. Sua dedicação era tal que, em algumas ocasiões, ele se viu obrigado a prestar esclarecimentos aos seus superiores, que tentavam refrear seus pedidos, principalmente aqueles que envolviam o dispêndio de recursos financeiros.

Antes de ser escolhido como responsável pela criação e organização do instituto de física da Universidade Católica carioca, Roser exerceu atividades docentes no Colégio Santo Inácio (RJ) e no Colégio Anchieta, em Nova Friburgo, cidade também localizada no estado fluminense. As atividades desenvolvidas pedagógicas por Roser no Colégio Santo Inácio e em Nova Friburgo foram as seguintes $[6]]^{3}$

1930-33 (Colégio St. Inácio): professor de cosmografia, ciências físicas e naturais, e matemática no Ginásio; professor de religião no curso preliminar. Encarregado do gabinete de física.

1940-46 (Nova Friburgo): professor de questões de física no filosofado, de física, química e astronomia no curso de ciências; professor de matemática superior; professor de língua alemã no curso de ciências; responsável dos exercícios em questões de física e matemática; orientador dos trabalhos científicos; encarregado do gabinete de física.

1947-49 (Colégio St. Inácio): professor de física do $7^{\circ}, 6^{\circ}$ e $5^{\circ}$ ano; responsável pelo gabinete de física e pelos museus de mineralogia e história natural.

Decidida a criação do instituto de ciências na Universidade Católica, Roser viu-se numa situação delicada, visto que os seus estudos de física, na Áustria, haviam sido realizados há já bastante tempo, além de que a sua formação científica tinha inevitáveis lacunas, devido ao tempo e energias inevitavelmente dispendidos com os estudos de teologia e a formação necessária para a sua ordenação sacerdotal. Para tornar sua situação ainda

\footnotetext{
3 Vejam-se, também, os Catálogos da Província Brasil Central dos anos correspondentes.
} 
mais difícil, o próprio conteúdo da física tinha mudado significativamente. Antes da Segunda Guerra Mundial, a física nuclear ainda estava na sua infância, situação radicalmente distinta daquela no pós 1945 . Consciente das lacunas em sua formação, Roser toma a decisão de passar algum tempo em algumas das melhores universidades dos Estados Unidos com o objetivo de aprofundar os seus conhecimentos tanto em física experimental como em física teórica ${ }^{4}$ Como mostram as cartas depositadas no arquivo da cúria dos jesuítas, Roser trabalhou incansavelmente, por vezes acima das suas possibilidades, para se colocar em condições de atender às determinações dos seus superiores jesuítas:

Vejo-me, hoje em dia, diante de tarefa imensa se quero recuperar tudo isto que não fiz na mocidade. Completamente não mais o conseguirei porque já estou sentindo a diferença de estar na universidade com trinta (30) e quarenta e cinco (45) anos (...). Eu sou o primeiro a sentir dentro de mim esta inadequação feita de falta de capacidade (e agora também falta de saúde). É preciso tomar as coisas como Deus as manda, contentar com isso e ir adiante com coragem 5

São várias as indicações que comprovam que Roser foi bem sucedido nos anos que passou nas Universidades de Chicago, Santa Clara, Stanford e Fordham. A sua pesquisa deu origem à publicação de vários artigos científicos (ver Apêndice). Além disso, assistiu a cursos, visitou laboratórios, adquiriu equipamentos científicos, redigiu planos de estudos e projetos de pesquisa para o futuro Instituto de Física na Universidade Católica, detalhando quais deveriam ser as qualidades intelectuais e humanas dos jovens jesuítas e leigos que o integrariam. Desenvolveu uma rede significativa de contatos e de colaboradores tendo em vista os seus planos para o Instituto de Física. Envolveu-se, também, numa intensa atividade pastoral, celebrando missas, batizados e orientando retiros espirituais.

O Instituto de Física da Universidade Católica foi criado em 1957, um ano após o regresso de Roser ao Brasil, sendo ele o seu primeiro diretor, cargo que ocupou até à sua morte inesperada, em 1967, devido a um afogamento na praia da Barra da Tijuca, zona oeste da capital fluminense.

\section{As atividades científicas}

Em agosto de 1941, o Padre Roser participou no congresso internacional de raios cósmicos, o qual foi organizado por Gleb Wataghin (1899-1986) na Escola Politécnica do Rio de Janeiro [7]. Trata-se do congresso

\footnotetext{
${ }^{4}$ Ver nota 16.

5 Carta de F. X. Roser ao Superior Provincial, Chicago, 25 de janeiro de 1950 (ACP).
}

em que esteve também presente o físico norte-americano Arthur H. Compton (1892-1962, Prêmio Nobel de Física em 1927) e membros da sua equipe [8] 6. O fato de que Roser apresentou um trabalho científico sobre o tema de sua tese, publicado nos Anais do evento, indica que ele tencionava integrar a pequena comunidade científica brasileira e assim dar prosseguimento à sua pesquisa em raios cósmicos [9]. Deverá também ter sido após o seu regresso da Áustria que ele conheceu Bernhard Gross (1905-2002), físico alemão radicado no Brasil desde meados de 1933, e que também iniciara a sua carreira científica no domínio dos raios cósmicos. A partir dessa época, Roser realizou algumas atividades ocasionais no Instituto Nacional de Tecnologia, onde trabalhava o colega alemão. Também nos anos 1940, Roser aproximou-se do físico carioca Joaquim da Costa Ribeiro (1906-1960), com quem manteria contato até ao final da vida deste último. A proximidade que existia entre ambos levou Roser homenagear postumamente Costa Ribeiro dando o seu nome ao Instituto de Física da PUC-Rio. Anos depois, Gross e Roser seriam colaboradores científicos próximos em investigações sobre o fallout radioativo. A citação abaixo sugere que Gross e Roser mantiveram relações que ultrapassavam o domínio estritamente científico:

De 20 a 30 de junho de 1944 esteve em Friburgo o Dr. Bernhard Gross, professor contratado pelo governo brasileiro para o Instituto de Tecnologia do Rio de Janeiro, cientista de nomeada internacional em vista de seus estudos sobre os raios cósmicos. O Prof. Gross veio a Friburgo a convite do Pe. Roser. As conferências com projeções versaram sobre problemas das radiações cósmicas. Hóspede do Colégio por mais de 10 dias, os filósofos ofereceram ao Prof. Gross uma Academia de despedida apresentando alguns pontos relacionados com a Física, a Matemática e a Filosofia [10].

As atividades docentes, de orientação dos estudantes jesuítas e as obrigações pastorais impediram Roser, naquela fase da sua vida, de dar continuidade à sua carreira em física. Existem evidências de que, durante a sua estadia no Colégio Anchieta, em Nova Friburgo, e no Colégio St. Inácio, no Rio de Janeiro, o Pe. Roser se esforçou por equipar os laboratórios de física e por adquirir novos livros para a biblioteca. Uma boa parte das cartas trocadas com o Provincial e com o Vice-Provincial durante este período versam sobre a compra de equipamento científico e também sobre a escassez de recursos financeiros. Por exemplo, a 11 de Outubro de 1946, o P. Roser escreveu ao Vice-Provincial, que iria participar numa reunião na Argentina, pedindo-lhe para adquirir o livro Física General, 5 Tomos, de R. G. Loyarte 7

\footnotetext{
6 A respeito da visita de Compton ao Brasil, cf. [8].

7 Carta de F. X. Roser ao Vice-Provincial, Nova-Friburgo, 11 de outubro de 1946 (ACP).
} 
Em algumas das mais de cem cartas que escreveu aos seus superiores e aos reitores da PUC-Rio, Roser teceu inúmeros comentários a respeito da sua formação universitária e também sobre as atividades que exerceu após o término do seu doutorado. Tais comentários revelam que as suas atividades docentes e pastorais não só o impediram de se manter a par das novidades científicas, como consumiram suas forças físicas. Resumidamente, o fato de ter passado vários anos a lecionar para alunos do nível ginasial ou para estudantes de teologia acabou por impedi-lo de se dedicar à consolidação de uma carreira científica, o que viria a ter um custo elevado, obrigando-o a recuperar o atraso numa idade já mais avançada, com impactos negativos na sua saúde. Anos mais tarde, ele se lamentaria disso, chegando inclusive a alertar os seus superiores para a necessidade de enviar mais precocemente para estudos avançados os jesuítas que deveriam dedicar-se à ciência:

De fato, trabalhei nos quatro primeiros anos de Friburgo com afinco para completar as muitas lacunas que me restavam (tendo passado por um curso universitário muito apressado e sobrecarregado). Antes de poder terminar o programa fui feito superior e depois vim para o Rio. Isto me prendeu de tal modo que substancialmente nada mais pude fazer de novo, ficando definitivamente desfalcado e impossibilitado de tomar parte em qualquer coisa que passasse um pouco do nível secundário. Tratei de despachar vários aspetos secundários como aprender eletrônica (graças a Deus, senão hoje me veria perdido), o inglês, os trabalhos no instituto de tecnologia, mas na linha principal nada pude fazer 8

Em 1948, Roser deslocou-se pela primeira vez aos Estados Unidos. Em 1950, regressou para um longo período de estudos, finalizado em 1956. Ao longo dos seis anos em que viveu, estudou e pesquisou em diferentes universidades e centros de pesquisa, Roser recorreu à rede de instituições jesuítas para conseguir sustentar-se. Durante um período de pouco mais de 12 meses, recebeu uma bolsa de estudos do CNPq.

Não é completamente claro o motivo da primeira viagem de Roser aos EUA, nem a duração da sua estadia. Tudo indica que ele se dirigiu àquele país para adquirir equipamento científico para algumas instituições de ensino mantidas pelos jesuítas e, principalmente, angariar fundos para custear as atividades pedagógicas da Companhia de Jesus no Brasil 99 Não é improvável, no entanto, que ele tenha viajado com o intuito de conhecer laboratórios e universidades norte-americanos com

\footnotetext{
8 Carta de F. X. Roser ao Superior Provincial, Chicago, 25 de janeiro de 1950 (ACP).

9 Carta de F. X. Roser ao Superior Provincial, New York, 05 de março de 1948 (ACP).
}

o objetivo de poder orientar adequadamente o futuro centro de ciências naturais da Universidade Católica, fundada em 1940, mas então ainda dedicada exclusivamente às humanidades. O propósito de Roser, já naturalizado brasileiro, era o de voltar a dedicar-se à física a nível profissional.

No ano seguinte, foi criado no Rio de Janeiro um centro de física que pretendia mudar radicalmente o cenário até então existente: o Centro Brasileiro de Pesquisas Físicas (CBPF), fundado por Cesar Lattes (1924-2005) [11] 10 José Leite Lopes (1918-2006) e Jayme Tiomno (1920-2011), e que contou com o apoio de pessoas de diferentes estratos da sociedade carioca. Entre os cientistas que apoiaram, desde o início, a fundação do CBPF encontrava-se o Pe. Roser, que viria a ser um dos membros fundadores daquela instituição. Aliás, em meados da década seguinte, ainda nos EUA, Roser comenta, em carta ao então reitor da PUC-Rio, o Padre Pedro Velloso (1902-1993), engenheiro de formação, que estava mantendo contatos com Lattes, uma vez que este último havia manifestado interessado numa técnica instrumental que o primeiro estava aprendendo nos EUA. Antes da crise de 1954, provocada por um desvio financeiro [12] ${ }^{11}$, Roser considerava seriamente a possibilidade de colaborar com o CBPF, uma vez que, desde 1950, ano em que chegou para a sua terceira viagem aos EUA, tinha recebido um pedido de Lattes para colaborar com o centro. Com a saída temporária de Lattes do CBPF, os seus planos tiveram que ser redirecionados:

\section{Recebi uma carta do diretor do Centro Bra- sileiro de Pesquisas Físicas em que ele me encarregava da sessão dos aparelhos (para medida de radioatividade e raio cósmico) no referido centro. Não sei se posso aceitar, mas sou atualmente o único que está a par desta nova técnica que entretanto se tornará ra- pidamente de grande importância na física 12}

Os seis anos (1950-1956) que passou nos EUA foram movimentados e produtivos. Roser, que no início desta etapa contava já com 45 anos, desenvolveu um plano de estudos e investigação que deu origem a resultados científicos de impacto. Isso sem descuidar as suas atividades pastorais, que exercia com gosto, mas que lá lhe eram ainda mais necessárias visto que a sua província, no Brasil, tinha dificuldades em lhe enviar dinheiro. Assim,

\footnotetext{
10 A respeito da carreira científica de Cesar Lattes, um dos nomes mais importantes da física brasileira no séc. XX, cf. [11].

11 Em 1954, tornou-se conhecido o desvio de verbas destinadas ao CBPF pelo CNPq para a constituição de expertise em física nuclear. Este desvio afetou seriamente ambas as instituições e levou o presidente do $\mathrm{CNPq}$ a renunciar ao seu cargo. O responsável pelo desvio, cujo nome acabou por se tornar público, foi Álvaro Diffini, professor de química da Universidade do Rio Grande do Sul e, à data, diretor executivo do CBPF. Esse evento está descrito em [12], pp. 202-219.

12 Carta de F. X. Roser ao Superior Provincial, Chicago, 30 de julho de 1950 (ACP).
} 
Roser desempenhava trabalhos pastorais que o ajudavam a assegurar a sua própria subsistência, aliviando os seus companheiros no Brasil. A vasta correspondência de Roser com os seus superiores e com o reitor da Universidade Católica deixam entrever as exigências de uma vida dedicada à pesquisa, exigências que ele exprime no desabafo: "Mas seja tudo pelo bem da física" 13

Em 1950, o P. Roser ingressou na Universidade de Chicago e recomeçou os estudos na área de raios cósmicos. Trabalhou com o físico Marcel Schein (1902-1960): "Junto com o Prof. Schein, Pe. Roser organizou uma rede de balões que subiam aos céus ante os jogos dos físicos e jogadores de baseball que deviam estar achando divertido aqueles homens crescidos a brincarem com balões, e que foram na verdade os primeiros passos para o estudo dos raios cósmicos nas grandes alturas." [Cf. Cullen [1], p. 123.] (Fig. 2) Neste tempo, o Pe. Roser assistiu a aulas e conferências de Enrico Fermi (1900-1954) e Willis E. Lamb (1913-2008) e interessou-se pelo problema de perda de energia de partículas ionizantes: "Para verificar a nova teoria de Fermi, usou a técnica, ainda nova, de cristais cintiladores. Investigou a possibilidade de usar tais cristais como contadores proporcionais para partículas de alta energia. No fim, usou anthraceno para medir a perda de energia de mesons- $\mu$, e comprovou experimentalmente,

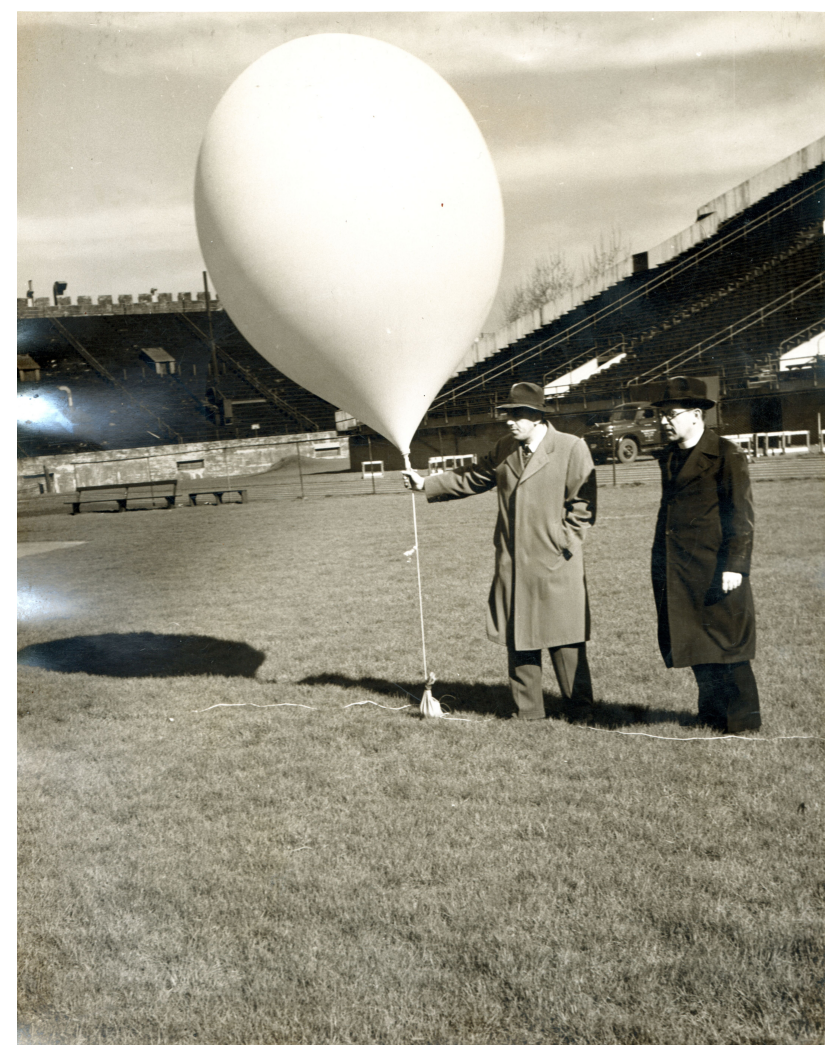

Figura 2: Roser (à dir.) e Schein (Chicago, 1950).

\footnotetext{
13 Carta de F. X. Roser ao Superior Provincial, Chicago, 19 de março de 1951 (ACP).
}

pela primeira vez, a Teoria de Fermi." 14 Concluiu um curso sobre radio-isótopos e instrumentos novos, em Oak Ridge, e depois iniciou uma viagem pela Europa a fim de iniciar contatos com os mais importantes laboratórios da época Cf. Cullen [1], p. 123.

Em 1952, foi admitido na Universidade de Stanford, onde trabalhou, durante um ano, no laboratório de Felix Bloch (1905-1983), físico suíço que desenvolveu a sua atividade sobretudo nos EUA, e que recebeu o Prémio Nobel da Física neste mesmo ano pelos seus trabalhos em ressonância magnética nuclear. Ainda neste ano, Roser deveria ter vindo ao Brasil para participar do Simpósio New Research Techniques in Physics, que aconteceu entre o Rio e São Paulo, com a participação de vários físicos internacionais, como Richard Gans (1880-1954), Marcel Schein, I. I. Rabi (1898-1988), Eugene Wigner (1902-1995), Guido Beck (1903-1988), além dos brasileiros Jayme Tiomno, José Leite Lopes, José Goldemberg (1928), entre outros. Sem que o próprio Roser entendesse a razão, até porque estava previsto que as suas despesas fossem cobertas pela organização do evento, a sua participação acabou por não se concretizar ${ }^{15}$

No ano seguinte, Roser trabalhou no laboratório de alta energia e micro-ondas da Universidade de Stanford, sob a orientação de Robert Hofstadter (1915-1990), físico norte-americano que recebeu o Prémio Nobel da Física em 1961, juntamente com Rudolf Mössbauer "pelos seus estudos pioneiros da dispersão em núcleos atómicos e pelas consequentes descobertas da estrutura dos nucleões." No laboratório de Hofstadter, levou a cabo trabalhos "sobre o mecanismo fundamental e sobre a eficiência de contadores a cintilação líquida e plásticos, por meio de contadores de grandes dimensões." [Cf. Cullen [1], p. 124]. Nesse período, publicou três artigos que tiveram uma boa recepção na comunidade científica 16

Roser sabia que não seria suficiente aprender novas técnicas em física experimental. Pesquisas consistentes e inovadoras nessa área exigiam que conhecesse, o melhor possível, os desenvolvimentos teóricos correspondentes. Neste sentido, as suas atividades acadêmicas incluíam assistir o maior número possível de cursos e seminários. Por exemplo, quando esteve em Standford assistiu a dois cursos de física nuclear lecionados por Robert Hofstader e um curso de Richard Feynman.

Durante um período de pouco mais de 12 meses, Roser desfrutou de uma bolsa de pesquisa concedida pelo então Conselho Nacional de Pesquisas (hoje CNPq) ${ }^{17}$ A ob-

14 Idem. Ver, também, carta de F. X. Roser ao Superior Provincial, Chicago, 01 de agosto de 1950 (ACP).

15 Ver carta de F. X. Roser ao Superior Provincial, Santa Clara, Califórnia, 17 de junho de 1952 (ACP); carta de F. X. Roser ao Superior Provincial, Santa Clara, Califórnia, 03 de agosto de 1952 $(\mathrm{ACP})$.

16 Segundo consulta ao site do PROLA, os três artigos que Roser publicou com Theodor Bowen receberam 40 citações. (https:// journals.aps.org/archive/), acessado em 23 de junho de 2017.

17 Numa carta dirigida ao Almirante Álvaro Alberto da Mota e Silva (1889-1976), Roser agradece a concessão da bolsa concedida pelo Conselho Nacional de Pesquisas, e descreve, de forma sucinta, os 
tenção da bolsa, que foi importante para que conseguisse adquirir mais livros e equipamento de laboratório para a PUC carioca, teve um preço: Roser foi obrigado a mudar de área de pesquisa, abandonando o tema dos momentos nucleares (sob a supervisão de Felix Bloch), e retomando a pesquisa em raios cósmicos.

Como já foi mencionado, durante a sua estadia nos EUA Roser não se preocupava apenas em aprender física. Em rigor, o aprofundamento da sua formação em física justificava-se pela incumbência recebida de organizar um instituto de física para a Universidade Católica carioca, que Roser considerava como a missão de sua vida. Nas muitas cartas enviadas ao Superior dos Jesuítas e ao Reitor da PUC, ele defendia que as ações mereciam ser concretizadas de tal modo que os seus resultados fossem realmente relevantes:

Existe um certo engano a respeito dos estudos acadêmicos e dos empreendimentos científicos. Representam um processo de maturação e de crescimento orgânico que não pode ser improvisado nem apressado além de um limite possível. Estou me esforçando para trabalhar até este limite. Mas me é impossível fazer os milagres para os quais nem a saúde nem as fracas forças intelectuais não me habilitam. Mais uma razão para treinar gente nossa, religiosa e secular, quanto antes e enquanto tiverem força na juventude ${ }^{18}$

Nas múltiplas cartas que escreveu aos seus superiores religiosos e ao reitor da Universidade Católica do Rio, o Pe. Roser manifesta insistentemente a sua preocupação com a formação de uma equipe de físicos bem preparados, jesuítas e leigos, que pudessem integrar o departamento de física ${ }^{19}$ Roser conseguiu realmente montar uma equipe

objetivos dos seus estudos nos EUA, em particular na Universidade de Stanford, bem como parte dos resultados alcançados. Vale a pena dar a voz ao próprio Pe. Roser: "Para a faculdade de ciências da Universidade Católica ser capaz de contribuir o seu quinhão, embora modesto, para esta remodelação de nosso ensino, é preciso que alguns dos seus membros com currículos tipo "pre-war" já mais antigo, tenham a oportunidade de poder fazer primeiro este reajustamento em sua própria formação antes de começar a transmiti-lo aos alunos. É, além disso, também o único caminho para prover estes alunos com o preparo adequado e necessário, no caso de alguns deles terem que seguir cursos de aperfeiçoamento em universidades estrangeiras, onde - de outro modo - teriam que gastar tempo e forças em longos períodos de adaptação ao novo ambiente e às suas exigências. Para corresponder a este objetivo tenho cursado todas as aulas de interesse no departamento de física e matemática (à razão de 4 ou 5 por dia) e tenho procurado me familiarizar com os métodos destes dois departamentos de reconhecida fama e eficiência (debaixo da orientação de Prof. Como Bloch, Schiff, Lamb, Panowsky, Hahr, Plya e outros)" (Stanford 19 de fevereiro de 1955 (NMPUC)).

18 Carta de F. X. Roser ao Superior Provincial, Santa Clara, Califórnia, 20 de abril de 1953 (ACP).

19 Por exemplo, na Carta que escreveu de Santa Clara, Califórnia, ao Reitor da Universidade Católica do Rio de Janeiro a 01 de Maio de 1954, o Pe. Roser afirma: "Tomo a liberdade de insistir, mais uma vez, em meu ponto costumeiro, tanto mais que o meu no Instituto de Física, mas não sem a inclusão de membros do Instituto de Biofísica da então Universidade do Brasil, hoje UFRJ.

Importa referir, finalmente, que Roser integrou, ainda nos EUA, a comitiva brasileira que participou de uma reunião na ONU que visava discutir os efeitos sobre a saúde humana dos dejetos radioativos. A partir dessa reunião, Roser passou a dedicar-se ao estudo das radiações naturais, no que foi auxiliado pelo físico norteamericano Thomas Lynch Cullen (1917-1985), também padre jesuíta. Cullen e Roser realizaram inúmeras medidas da radioatividade natural em diferentes regiões brasileiras, sobretudo nos Estados de Minas Gerais e Espírito Santo. (Fig. 3)

A partir da década de 1970, o Departamento de Física da PUC Rio consolidou-se como um dos mais importantes centros de formação e pesquisa em física na América Latina. A morte prematura do Pe. Roser impediu-o de participar no processo de crescimento e consolidação do instituto de física que ele próprio fundara e que havia sido transformado em departamento na sequência da reforma universitária. O seu sucessor foi Thomas Lynch Cullen, seu colaborador havia alguns anos. Cullen seria o principal responsável pela contração dos físicos que deram ao departamento de física da PUC-Rio a estatura que lhe viria a ser reconhecida. Entre eles, podem ser mencionados os nomes de Erasmo Ferreira, Nicim Zagury, Sérgio Machado Rezende, Jayme Tiomno, Jorge André

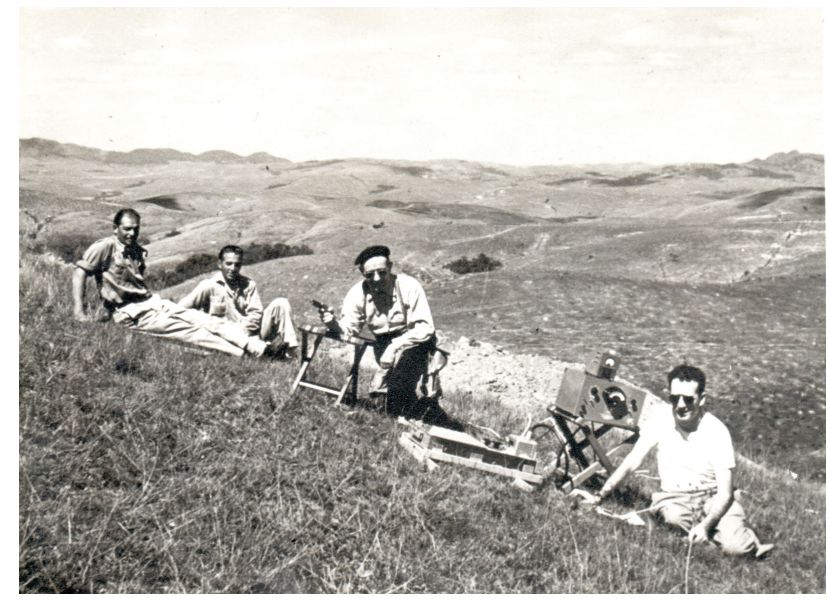

Figura 3: Cullen ( $1^{\circ}$ à dir.), Roser $\left(2^{\circ}\right.$ à dir.) e desconhecidos (Morro do Ferro, Poços de Caldas, Minas Gerais, 1956).

tempo por aqui está chegando ao fim; seria muito conveniente fazer planos definitivos antes de sair. O problema é o seguinte: para se organizarem e fazerem funcionar os laboratórios da universidade e para se levar adiante alguma pesquisa, é preciso ter, absolutamente, alguma ajuda - na pessoa de alguém que esteja bem versado em métodos modernos de laboratório e que tenha prática na técnica de circuitos eletrónicos e alto vácuo: e que, por cima, possa dirigir trabalhos de laboratório de alunos segundo linhas modernas. (...) A questão é de achar-se alguém que realmente queira dedicar-se à universidade de modo que se possa contar com ele para mais serviço do que apenas dar aulas de corrida" (NMPUC). 
Swieca (1936-1980), Antonio Luciano Leite Videira e Sarah de Castro Barbosa.

\section{Conclusão}

Em retrospecto, a trajetória de vida do Padre Francisco X. Roser não se distingue, na prática, de uma carreira científica levada a cabo por um leigo. Sua dedicação à ciência, a seriedade com que se entregava às suas múltiplas atividades, a preocupação que mostrava com a organização adequada do instituto de física, entre outras características, são próprias de qualquer cientista competente e apaixonado. No entanto, quando nos lembramos de que, a par dos seus trabalhos de pesquisa, Roser se dedicava, simultaneamente, às atividades próprias de um sacerdote católico, os seus esforços ganham outra tonalidade. Na verdade, nem sempre lhe foi fácil equilibrar a carreira científica com as obrigações eclesiásticas. No entanto, as suas cartas, aqui exploradas de modo inevitavelmente econômico, não deixam margem para dúvida de que dedicou mais tempo, energia e concentração à sua carreira científica do que às suas funções estritamente sacerdotais. Aliás, mesmo a atividade docente, durante o período em que esteve na PUC-Rio, parece ter sido relegada para segundo plano. Docentes ainda hoje atuantes no departamento de física da PUC não se lembram de Roser em sala de aula. Tal não deve ser entendido, contudo, como se ele considerasse a docência uma tarefa de menor importância. Pelo contrário, Roser esteve à frente, por exemplo, da contratação do francês Pierre Henrie Lucie (1917-1985), um entusiasta das questões ligadas ao ensino, além de um professor notável, capaz de influenciar inúmeras gerações de estudantes. A sua missão era a construção de um departamento científico que atendesse as exigências da ciência contemporânea sem que se descuidasse dos princípios e valores inacianos.

O mérito científico do Pe. Roser foi amplamente reconhecido no Brasil e no exterior. Em setembro de 1952, ingressou na Academia Brasileira de Ciências como membro titular ${ }^{20}$ Doze anos depois, o governo austríaco o agraciou com a Cruz de Honra austríaca pela ciência e arte.

Recordar a trajetória de Francisco Xavier Roser é importante, não só porque ele foi o fundador do atual Departamento de Física da PUC-Rio e sua principal liderança até o seu desaparecimento precoce com 62 anos de idade, mas também porque esta deixa patente as qualidades necessárias a quem desejar empreender uma carreira científica. O seu exemplo continua sendo inspirador devido à sua persistência, à sua notável dedicação, à sua capacidade de colaboração, à sua percepção de que a ciência era um fator fundamental para o desenvolvimento integral das nações e, acima de tudo, pelo seu inegável amor à física. (Fig. 4)

20 Carta de F. X. Roser ao Superior Provincial, Santa Clara, Califórnia, 13 de setembro de 1952 (ACP).

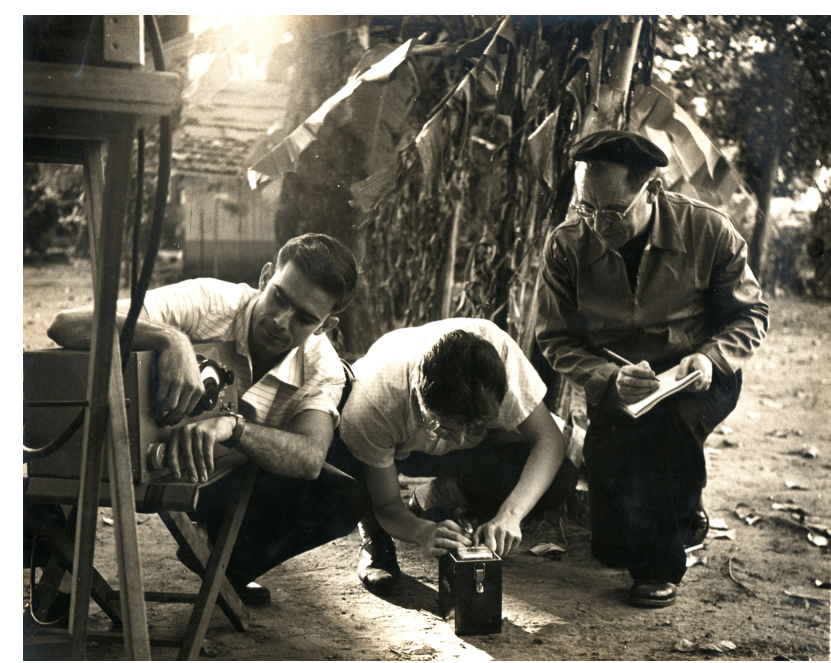

Figura 4: Pe. Roser e colaboradores realizando medidas de radioatividade natural, local e data ignorados.

\section{Agradecimentos}

Os autores agradecem aos responsáveis pelo Arquivo da Cúria Provincial da Província Brasileira da Companhia de Jesus, Pe. José Luis Fuentes, SJ e Ir. Geraldo Luiz de Castro, SJ, pela ajuda concedida na pesquisa do material arquivístico. O apoio dado pelo Núcleo de Memória da PUC-Rio, na figura de Clóvis Gorgônio, foi também importante, sobretudo pela gentil disponibilização de documentos. A bibliotecária Cláudia Furtado, Colégio Santo Inácio (RJ), facultou o acesso aos anuários desta instituição de ensino e enviou cópias de fotografias. Finalmente, as conversas com os Professores Pedro Guimarães Ferreira, SJ, Ênio Frota da Silveira e Vera Baltar contribuiriam para o esclarecimento sobre a personalidade e a contribuição acadêmica do Pe. Roser. Um dos autores (AAPV) agradece a bolsa de produtividade concedida pelo CNPq, ao Programa Prociência UERJ/FAPERJ e ao Centro Brasileiro de Pesquisas Físicas pelo apoio dispensado ao longo da pesquisa.

\section{Material suplementar}

O seguinte material suplementar está disponível online: Apêndice - Relação de alguns artigos científicos de Francisco X. Roser

\section{Referências}

[1] A. Pinho, Ciência e Cultura 19, 608 (1967); P.M.G. Ferreira, Jesuítas Julho-Agosto-Setembro, p. 29 (2010); T.L. Cullen, Revista Verbum XXIV, 121 (1967); F. Dokulil e A. Prochaska (eds) in: Jesuítas Austríacos no Brasil Centro Leste (Colégio S. Luís, S. Paulo, 1992).

[2] [s.a.], Fluch oder Segen des Atoms, Blätter der österreischischen Jesuiten, Juni, p. 1 (1957).

[3] A. Udías, Los Jesuitas y la Ciência: Una Tradición en la Iglesia (Editorial Mensajero, Bilbao, 2014); Idem, Jesuit 
Contribution to Science: A History (Springer, London, 2015); M. Feingold (ed), The New Science and Jesuit Science: Seventeenth Century Perspectives (Kluwer Academic Publishers, Dordrecht, 2003); A. Dinis, A Jesuit Against Galileo? The Strange Case of Giovanni Battista Riccioli Cosmology, edited by A. Balsas and R.B. Batista (Axioma - Publicações da Faculdade de Filosofia, Braga, 2017); C. Fiolhais, Gazeta de Física 40, 25 (2017).

[4] V.F. Hess, Physical Review 57, 781 (1940).

[5] H. de Lima Vaz, Biografia (1976), disponível em http://www.padrevaz.com.br/index.php/biografia/ textos-autobiograficos/225-biografia-redigidano-ano-de-1976, acesso em 5 de maio de 2017.

[6] P.A. Maia e P.N. Braga, Pe. Francisco Xavier Roser (1904-1967) (Centro Cultural João XXIII, Rio de Janeiro, 2003), p. 10.

[7] E.F. da Silveira, AIP Conference Proceedings 1529, 10 (2013).

[8] O. Freire Jr e I. Silva, Revista Brasileira de História 34, 181 (2014); A.A.P. Videira e C.L. Vieira, Reflexões sobre Historiografia e História da Física no Brasil (Editora Livraria da Física, São Paulo, 2010).

[9] F.X. Roser, Symposium sôbre Raios Cósmicos. Academia Brasileira de Ciências (Anais da Academia Brasileira de Ciências, Rio de Janeiro, 1943), p. 105.

[10] P.A. Maia, Síntese Nova Fase 18, p. 405 (1991).

[11] C.L. Vieira and A.A.P. Videira, Physics in Perspective 16, 3 (2014).

[12] A.M.R. de Andrade, Físicos, Mésons e Política: a Dinâmica da Ciência na Sociedade (HUCITEC/MAST/CNPq, São Paulo/Rio de Janeiro, 1999). 